\title{
Electronic and Steric Control of the Spin-Crossover Behavior in $[\mathrm{Mn}(\mathrm{CpR}) 2]$ Manganocenes
}

\author{
Jordi Cirera* and Eliseo Ruiz \\ Departament de Química Inorgànica i Orgànica, and \\ Institut de Recerca de Química Teòrica i Computacional, Universitat de Barcelona, \\ Diagonal 645, 08028 Barcelona, Spain \\ Email corresponding author: jordi.cirera@qi.ub.es
}

\begin{abstract}
A computational study of the spin-crossover behavior in the family of $\left[(\mathrm{CpR})_{2} \mathrm{Mn}\right](\mathrm{R}$ $=\mathrm{Me},{ }_{i} \mathrm{Pr}$ and $\left.{ }_{t} \mathrm{Bu}\right)$ is presented. Using the OPBE functional, the different electronic and steric effects over the metal's ligand field are studied, and trends on the transition temperature $\left(\mathrm{T}_{1 / 2}\right)$ behavior are presented in terms of the cyclopentadienyl $(\mathrm{Cp})$ ligand functionalization. Our calculations outlined a delicate balance between both, electronic and steric effects. While increasing the number of electron donating groups increases the transition temperature $\left(\mathrm{T}_{1 / 2}\right)$ until the point that the transition is suppressed and only the low-spin state is observed, steric effects play the opposite role, increasing the distance between the $\mathrm{Cp}$ rings, which in turns shifts $\mathrm{T}_{1 / 2}$ to lower values, eventually stabilizing the high-spin state. Both effects can be rationalized by exploring the electronic structure of such systems in terms of the relevant d-based molecular orbitals.
\end{abstract}

Keywords: Manganocenes, Spin-Crossover, Transition Temperature, Molecular Orbitals, Density Functional Theory 


\section{Introduction}

Metallocenes are one of the most iconic molecules in organometallic chemistry. Since the discovery of ferrocene by Pauson and Miller,1,2 this type of sandwich compounds has been extensively studied,3-5 and prepared with several first row transition metal ions such as vanadium, 6 chromium, 7 manganese, 8 cobalt and nickel. 9,10 Although metallocenes are widely used in organic synthesis and catalytic cycles, with some derivatives showing activity in industrially relevant applications such as olefin polymerization, 3 little less emphasis has been devoted to the study of electronically governed properties in such systems. Among them, spin-crossover, a phenomenon in where the spin state of the metal center changes due to the action of an external stimuli,11 is of particular relevance due to the potential use of such systems as molecular level switches. Among the different metallocenes from the first row, d5 manganocene derivatives of general formula $\left[(\mathrm{CpR})_{2} \mathrm{Mn}\right]$ have been widely studied.8 While some of these molecules are high-spin systems, such as the $\left[\left(\mathrm{Cp}_{1,3,4-}\right.\right.$ $\left.{ }_{\mathrm{tBu}}\right)_{2} \mathrm{Mn}$ ] molecule, 12 with a magnetic moment of $5.9 \mu \mathrm{B}$, some others have been reported to be low-spin systems, such as the $\left[(\mathrm{Cp} *)_{2} \mathrm{Mn}\right]$ molecule, with a temperature independent magnetic moment of $2.18 \mu$ в.13 The possibility of accessing two alternative spin-states points out, therefore, to the potential design of manganocene molecules exhibiting spin-crossover, and in fact, this has been reported in the literature through the years.8, 12,14 However, as it also occurs for many other families of spin-crossover systems, the link between the chemical functionalization of the ligand and the physical properties of the system is buried under several competing effects. In fact, as it was already introduce by Andersen and co-workers, 12 two competing effects are at play for the $\left[(\mathrm{CpR})_{2} \mathrm{Mn}\right]$ family. On one hand, electron 
donor groups (i.e, methyl, isopropyl, tert-butyl, etc..) stabilize the low-spin state. However, too much steric congestion seems to play the opposite effect, stabilizing the high-spin state. To which extend each effect is at play remains not clear, and therefore, the rational design of manganocenes with selected spin-crossover properties still elusive.

In this paper, we present a computational approach to study spin-crossover in manganocenes of general formula $\left[(\mathrm{CpR})_{2} \mathrm{Mn}\right]\left(\mathrm{R}=\mathrm{Me},{ }_{\mathrm{i}} \mathrm{Pr}\right.$ or $\left.{ }_{\mathrm{t}} \mathrm{Bu}\right)$. The computational methodology allows us to correctly model the spin-crossover behavior in such systems, as well as calculate with accuracy the corresponding transition temperatures when available. Moreover, by inspecting the underlying electronic structure of different members of this family, it is possible to determine the effect that ligand functionalization has over the transition temperature, and therefore over the spin-crossover behavior in such systems, much in the way that has been done for other families of spin-crossover molecules.15-17 This paper is organized as follows: first, we will present the computational methodology, and the results for several members of the $\left[(\mathrm{CpR})_{2} \mathrm{Mn}\right]$ family. Then a discussion of the data will be done, and finally, the conclusions will be outlined

\section{Methodology}

All Density Functional Theory (DFT) calculations were carried out with Gaussian 09 (revision D.01)18 electronic structure package with a 10-8 convergence criterion for the density matrix elements, using the hybrid GGA functional OPBE.19-22 This functional has been previously used to model Spin-Crossover processes in other transition metal compounds,23-30 and although we have been very successful in modeling SCO processes using the meta-hybrid TPSSh31, 32 functional,15-17 for the 
particular case of $\left[\mathrm{Mn}(\mathrm{CpR})_{2}\right]$ systems OPBE provides with the correct ground state, while the TPSSh functional overstabilizes the high-spin state (see SI). The fully optimized contracted triple- $\zeta$ all electron Gaussian basis set developed by Ahlrichs and co-workers with polarization functions was employed for all the elements. 33 The studied systems have been fully optimized in both spin states (see SI for optimized structures) and the subsequently vibrational analysis was performed. These results can later be used to compute thermochemical quantities from which one can extract the corresponding transition temperatures for each system, when possible.15 By fitting the $\Delta \mathrm{G} v s . \mathrm{T}$ data, one can extract the corresponding transition temperatures $\left(\mathrm{T}_{1 / 2}\right)$ for each calculated system. All the fitting parameters together with the corresponding correlation coefficient can be found in the SI. All time-dependent density functional theory (TD- DFT) 34 calculations were performed on the low-spin optimized molecules. It is well-known that, although DFT methods provide relatively accurate energy gaps, more reliable energies for this quantity can be obtained using TD-DFT, which accounts for electron relaxation. 35

\section{Results}

In this work, we have analyzed three different families of manganocenes, in which the cyclopentadienyl ring was being functionalized with the methyl (-Me), isopropyl (-iPr) and tert-butyl $(-\mathrm{tBu})$ groups. For each one of these compounds, we have fully optimized both the low- and high-spin states in order to study their potential spin-crossover behavior. In Table 1, the most relevant geometric parameters for each one of the studied compounds can be found. As can be seen from these data, the functionalization of the $\mathrm{Cp}$ - with methyl groups has almost no effect in the cyclopentadienyl to manganese bond lengths in the low-spin state, with ring centroid 
to metal distances ranging from $1.693 \AA$ to $1.702 \AA$ (an overall increase in the bond lengths of only $0.53 \%$ ). On the other hand, the functionalization of the ligands with isopropyl or tert-butyl has a much larger effect on the metal-ligand bond lengths. Adding Isopropyl groups increases the Cp-Mn bond length from $1.695 \AA$ to $1.749 \AA$ (increase of $3.2 \%$ ) and tert-butyl enlarges the metal-ligand bond length from $1.703 \AA$ to $1.774 \AA$ (and increase of $4.2 \%$ ). Moreover, when this bond lengths are compared with the $\left[(\mathrm{Cp})_{2} \mathrm{Mn}\right]$ in the low-spin state, the methyl functionalized systems remain quite close, while the isopropyl and tert-butyl systems suffer progressives increases of their metal-ligand bond lengths. 


\begin{tabular}{|c|c|c|c|c|c|c|}
\hline System & $S$ & $\mathrm{~d}\left(\mathrm{Mn}-\mathrm{Cp}_{1}\right)$ & $\mathrm{d}\left(\mathrm{Mn}-\mathrm{Cp}_{2}\right)$ & $\mathrm{d}(\mathrm{Mn}-\mathrm{Cp})$ & $\alpha$ & $\tau$ \\
\hline$\left[(\mathrm{Cp} 1-\mathrm{Me})_{2} \mathrm{Mn}\right]$ & $1 / 2$ & 1.692 & 1.693 & 1.693 & 178.98 & 9.16 \\
\hline$\left[(\mathrm{Cp} 1-\mathrm{Me})_{2} \mathrm{Mn}\right]$ & $5 / 2$ & 2.051 & 2.050 & 2.051 & 162.91 & 28.72 \\
\hline$\left[(\mathrm{Cp} 1,3-\mathrm{Me})_{2} \mathrm{Mn}\right]$ & $1 / 2$ & 1.695 & 1.698 & 1.697 & 178.92 & 2.62 \\
\hline$\left[\left(\mathrm{Cp}_{1,3-\mathrm{Me}}\right)_{2} \mathrm{Mn}\right]$ & $5 / 2$ & 2.051 & 2.043 & 2.047 & 163.24 & 45.78 \\
\hline$\left[\left(\mathrm{Cp}_{1,3,4-\mathrm{Me}}\right)_{2} \mathrm{Mn}\right]$ & $1 / 2$ & 1.702 & 1.702 & 1.702 & 179.19 & 2.73 \\
\hline$\left[(\mathrm{Cp} 1,3,4-\mathrm{Me})_{2} \mathrm{Mn}\right]$ & $5 / 2$ & 2.051 & 2.050 & 2.051 & 163.48 & 31.55 \\
\hline$\left[\left(\mathrm{Cp}_{1,2,3,4-\mathrm{Me}}\right)_{2} \mathrm{Mn}\right]$ & $1 / 2$ & 1.707 & 1.707 & 1.707 & 177.63 & 0.42 \\
\hline$\left[(\mathrm{Cp} 1,2,3,4-\mathrm{Me})_{2} \mathrm{Mn}\right]$ & $5 / 2$ & 2.048 & 2.049 & 2.049 & 177.63 & 31.55 \\
\hline$\left[\left(\mathrm{Cp}_{1-\mathrm{iPr}}\right)_{2} \mathrm{Mn}\right]$ & $1 / 2$ & 1.695 & 1.694 & 1.695 & 177.78 & 4.88 \\
\hline$\left[\left(\mathrm{Cp}_{1-\mathrm{i} P r}\right)_{2} \mathrm{Mn}\right]$ & $5 / 2$ & 2.053 & 2.056 & 2.055 & 163.95 & 8.68 \\
\hline$\left[(\mathrm{Cp} 1,3-\mathrm{iPr})_{2} \mathrm{Mn}\right]$ & $1 / 2$ & 1.716 & 1.719 & 1.718 & 175.23 & 10.44 \\
\hline$\left[\left(\mathrm{Cp}_{1,3-\mathrm{iPr}}\right)_{2} \mathrm{Mn}\right]$ & $5 / 2$ & 2.064 & 2.059 & 2.062 & 159.59 & 5.86 \\
\hline$\left[(\mathrm{Cp} 1,3,4-\mathrm{iPr})_{2} \mathrm{Mn}\right]$ & $1 / 2$ & 1.751 & 1.747 & 1.749 & 177.15 & 11.88 \\
\hline$\left[(\mathrm{Cp} 1,3,4-\mathrm{iPr})_{2} \mathrm{Mn}\right]$ & $5 / 2$ & 2.111 & 2.143 & 2.127 & 170.31 & 48.06 \\
\hline$\left[(\mathrm{Cp} 1-\mathrm{tBu})_{2} \mathrm{Mn}\right]$ & $1 / 2$ & 1.703 & 1.703 & 1.703 & 180.00 & 35.98 \\
\hline$\left[(\mathrm{Cp} 1-\mathrm{tBu})_{2} \mathrm{Mn}\right]$ & $5 / 2$ & 2.061 & 2.061 & 2.061 & 180.00 & 36.11 \\
\hline$\left[\left(\mathrm{Cp}_{1,3-\mathrm{tBu}}\right)_{2} \mathrm{Mn}\right]$ & $1 / 2$ & 1.728 & 1.732 & 1.730 & 174.72 & 12.99 \\
\hline$\left[\left(\mathrm{Cp}_{1,3-\mathrm{tBu}}\right)_{2} \mathrm{Mn}\right]$ & $5 / 2$ & 2.071 & 2.071 & 2.071 & 161.77 & 16.92 \\
\hline$\left[(\mathrm{Cp} 1,3,4-\mathrm{tBu})_{2} \mathrm{Mn}\right]$ & $1 / 2$ & 1.774 & 1.774 & 1.774 & 177.01 & 8.78 \\
\hline$\left[(\mathrm{Cp} 1,3,4-\mathrm{tBu})_{2} \mathrm{Mn}\right]$ & $5 / 2$ & 2.123 & 2.128 & 2.126 & 172.95 & 6.17 \\
\hline
\end{tabular}

Table 1: DFT Calculated geometrical parameters for the $\left[(\mathrm{Cp} R)_{2} \mathrm{Mn}\right]\left(\mathrm{R}=\mathrm{Me},{ }_{i} \mathrm{Pr}\right.$ and $\left.{ }_{t} \mathrm{Bu}\right)$ studied systems. The average distance is indicated as $\mathrm{d}(\mathrm{Mn}-\mathrm{Cp})$. All distances in $\AA$. $\alpha$ is the angle between one Cp centroid, the manganese and the other Cp centroid. $\tau$ indicates the torsion angle between the Cp rings. Both parameters are in degrees.

From the above data, it is clear that the functionalization of the cyclopentadienyl ring with methyl groups does not play a significant steric effect, but rather, any change in the electronic properties of the studied systems will derive from the electron donating character that the methyl groups will have over the aromatic rings. Opposite to that, the functionalization of the ligands with ${ }_{i} \operatorname{Pr}$ and ${ }_{t} \mathrm{Bu}$ groups has 
a much larger steric component, and thus, it is expected that changes in the spincrossover behavior of such systems can be traced back to this steric component.

For all studied systems, the corresponding transition temperature has been computed by fitting the thermal dependence of the Gibbs free energy. The corresponding results as well as energy differences between both spin states and the approximated energy gap between orbitals can be found in table 2 .

\begin{tabular}{l|c|c|c}
\hline \multicolumn{1}{c|}{ System } & $\Delta \mathrm{E}_{(\mathrm{HS}-\mathrm{LS}) / \mathrm{kcal} \cdot \mathrm{mol}_{-1}}$ & $\mathrm{~T}_{1 / 2} / \mathrm{K}$ & $\Delta / \mathrm{cm}-1$ \\
\hline$\left[(\mathrm{Cp})_{2} \mathrm{Mn}\right]$ & 7.40 & 345 & 16504 \\
{$\left[(\mathrm{Cp} 1-\mathrm{Me})_{2} \mathrm{Mn}\right]$} & 9.10 & 449 & 16707 \\
{$\left[(\mathrm{Cp} 1,3-\mathrm{Me})_{2} \mathrm{Mn}\right]$} & 10.56 & 529 & 16888 \\
{$\left[(\mathrm{Cp} 1,3,4-\mathrm{Me})_{2} \mathrm{Mn}\right]$} & 11.56 & 551 & 17124 \\
{$\left[(\mathrm{Cp} 1,2,3,4-\mathrm{Me})_{2} \mathrm{Mn}\right]$} & 12.31 & 629 & 17221 \\
{$\left[(\mathrm{Cp} 1-\mathrm{iPr})_{2} \mathrm{Mn}\right]$} & 8.71 & 430 & 16757 \\
{$\left[(\mathrm{Cp} 1,3-\mathrm{Pr})_{2} \mathrm{Mn}\right]$} & 6.84 & 306 & 16155 \\
{$\left[(\mathrm{Cp} 1,3,4-\mathrm{Pr})_{2} \mathrm{Mn}\right]$} & 0.71 & - & 15405 \\
{$\left[(\mathrm{Cp} 1-\mathrm{tBu})_{2} \mathrm{Mn}\right]$} & 7.08 & 353 & 16854 \\
{$\left[(\mathrm{Cp} 1,3-\mathrm{tBu})_{2} \mathrm{Mn}\right]$} & 5.07 & 260 & 16056 \\
{$\left[(\mathrm{Cp} 1,3,4-\mathrm{BBu})_{2} \mathrm{Mn}\right]$} & -3.75 & - & 14844 \\
\hline
\end{tabular}

Table 2: Energy difference between the high- and low-spin states (in kcal/mol, positive value indicates low-spin ground state) for the studied $\left[(\mathrm{CpR})_{2} \mathrm{Mn}\right](\mathrm{R}=\mathrm{Me}$, ${ }_{i} \operatorname{Pr}$ and $\left.{ }_{t} \mathrm{Bu}\right)$ systems, with the corresponding transition temperature $\left(\mathrm{T}_{1 / 2}\right.$, in $\left.\mathrm{K}\right)$ and energy gap between non-bonding and antibonding orbitals (in $\mathrm{cm}-1$ ).

The first result that can be outlined from Table 2 is the different electron donor character of the $-\mathrm{H},-\mathrm{Me},-i \mathrm{Pr}$ and ${ }_{-t} \mathrm{Bu}$ groups. The single functionalization of the cyclopentadienyl ligand with each one of these substituents has the expected effect over the orbital splitting due to the increasing electron donor character of these substituents. This effect can be better observed by plotting the energy gap between non-bonding and the antibonding orbitals as a function of the Taft's equation $\sigma^{*}$ value, 
a parameter that measures the field and inductive effects of the substituent (Figure 1). However, bulkier substituents such as $-i \mathrm{Pr}$ and ${ }_{-t} \mathrm{Bu}$ groups already shown the competitive effect that sterics has over the electronic effects. By plotting the energy gap between the high-spin and low-spin states against the same $\sigma^{*}$ value, one can observe that, if indeed this energy gap increases with the -Me functionalization, inclusion of ${ }_{-i} \mathrm{Pr}$ and ${ }_{t} \mathrm{Bu}$ groups leads to smaller energy differences, which in turns leads to smaller transition temperatures. These results highlight the subtle equilibrium between both effects in terms of tuning the $\mathrm{T}_{1 / 2}$ in the family of $\left[(\mathrm{CpR})_{2} \mathrm{Mn}\right]$ compounds.
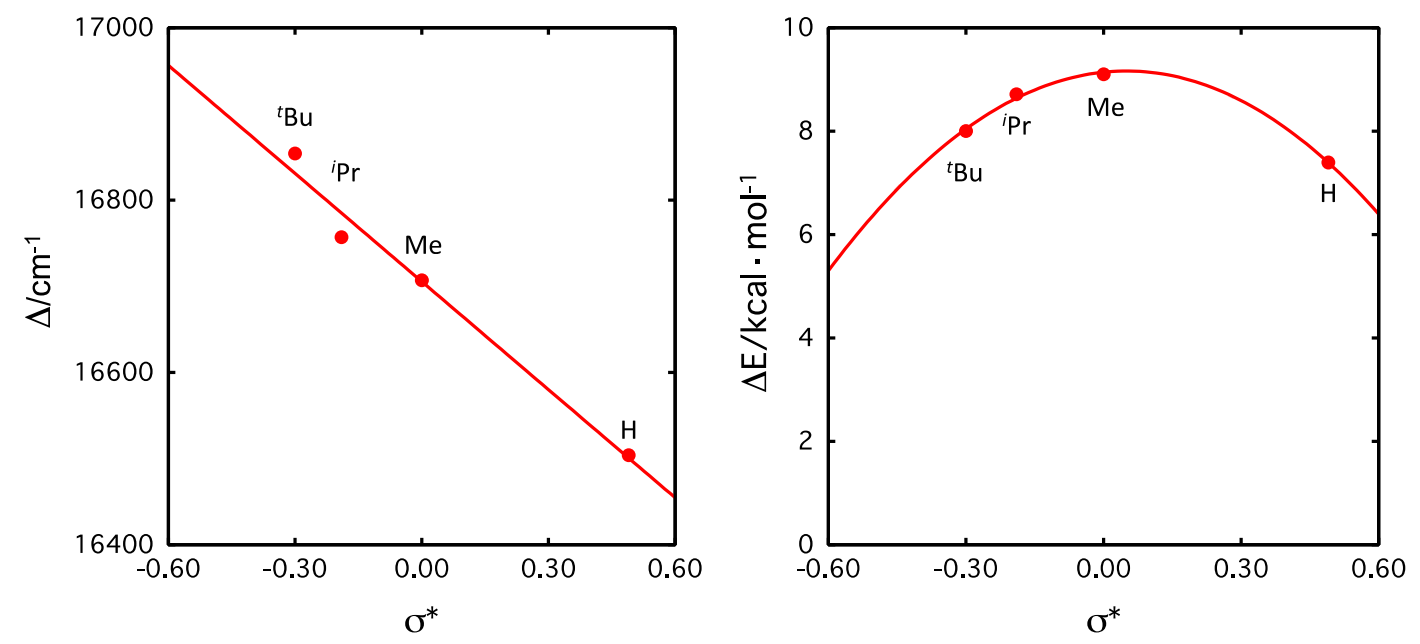

Figure 1: Left, energy gap between non-bonding and antibonding orbitals as a function of the Taft's $\sigma^{*}$ value for the $[(\mathrm{Cp} 1-\mathrm{R}) 2 \mathrm{Mn}]\left(\mathrm{R}=-\mathrm{H},-\mathrm{Me},-{ }_{i} \mathrm{Pr}\right.$ or $\left.{ }_{-t} \mathrm{Bu}\right)$ family. Right, energy gap between the high- and low-spin states for the same systems as function of $\sigma^{*}$.

Results in Table 2 can be correlated with the geometrical parameters for the studied systems to gain further insight into the different effects at play over the spincrossover behavior of the studied molecules. As can be seen in Figure 2, two different regimes can be observed, depending on if the functionalization is done with methyl groups, or if the functionalization is done with isopropyl or tert-butyl groups, this is, if the spin-crossover behavior is modulated by electronic effects, or by steric effects, as will be discussed later. 

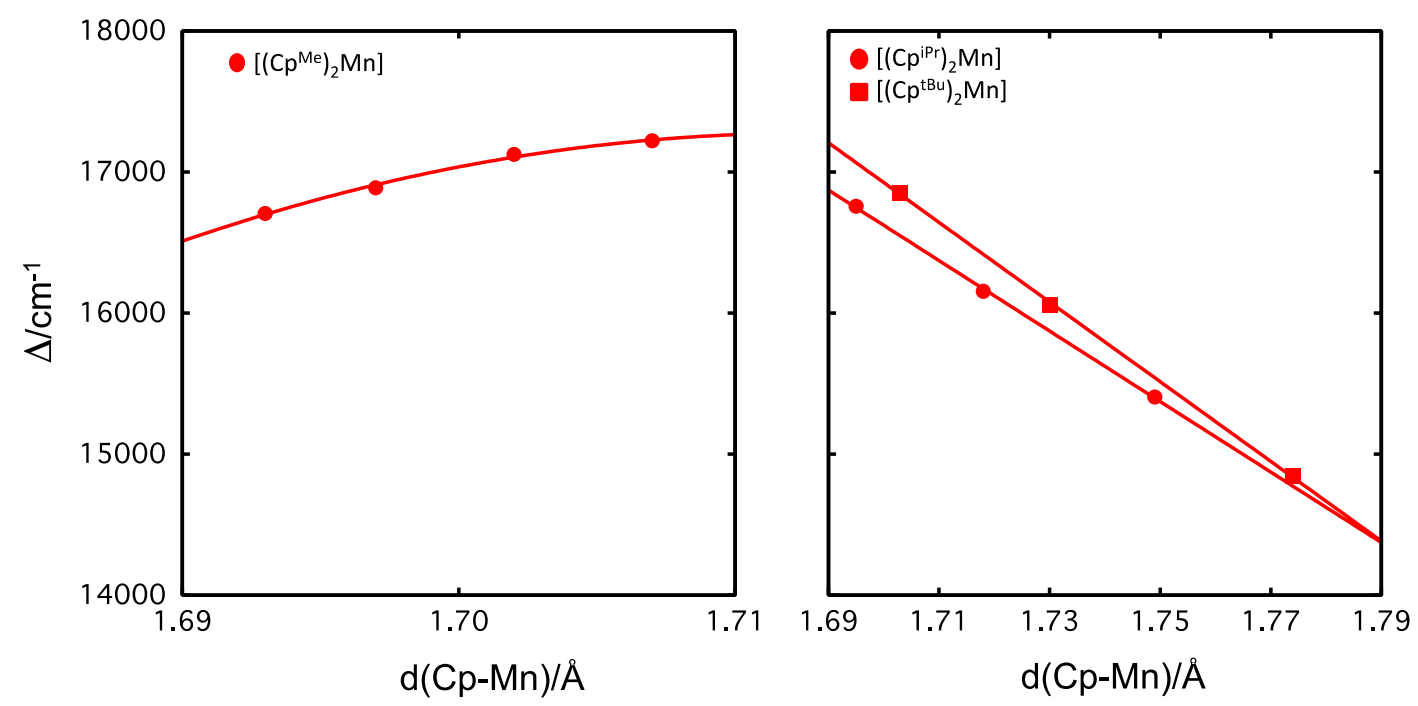

Figure 2: Correlation between the average distance $\mathrm{CpR}-\mathrm{Mn}\left(\mathrm{R}=-\mathrm{Me},-{ }_{i} \mathrm{Pr}\right.$ or $\left.{ }_{-t} \mathrm{Bu}\right)$, measured as the Mn to centroid distance, and the energy gap between non-bonding and antibonding orbitals.

Figure 2 illustrates the electron donor nature of the methyl substitution into the cyclopentadienyl ring. As can be seen from Figure 2 and Table 1, there is very little influence over the Mn-Cp bond length in the low-spin state with the increasing number of methyl groups added to the cyclopentadienyl ligand (bond lengths between 1.69 and $1.71 \AA$ ). However, a significant increase of the energy gap between the nonbonding and antibonding orbitals can be observed, as well as systematic increase in the corresponding computed transition temperatures as a result of the electron donor effect of the methyl groups (see Table 2). This effect can be also observed when comparing the systems $\left[(\mathrm{Cp})_{2} \mathrm{Mn}\right]$ and $\left[\left(\mathrm{Cp}_{1-\mathrm{Me}}\right)_{2} \mathrm{Mn}\right]$. While in both cases the geometrical parameters are almost identical in terms of bond lengths, a significant increase of the energy gap is observed just by adding one methyl group to the $\mathrm{Cp}$ ligand. Moreover, this chemical modification comes with a significant increase of the estimated $\mathrm{T}_{1 / 2}$ between both systems (see Table 2). In contrast, isopropyl and tert- 
butyl functionalization of the $\mathrm{Cp}$ ligand leads to a progressive decrease in the calculated $\mathrm{T}_{1 / 2}$. Although both groups are also electron donor, like the methyl group, the steric contribution takes over and, as can be seen from Figure 2 and Table 2, a progressive increase in the $\mathrm{Mn}-\mathrm{Cp}$ bond length is observed, which leads to smaller energy gaps between the sets of d-based orbitals, and ultimately to the suppression of the SCO behavior. In fact, the $\left[\left(\mathrm{Cp}_{1,3,4-\mathrm{tBu}}\right)_{2} \mathrm{Mn}\right]$ system has already a $\mathrm{S}=5 / 2$ ground state, as a result of the significant metal to ligand bond length enlargement, which generates a sufficiently small ligand field such as to favor the high-spin state.

A close inspection of the generated data also allows us to extract the limit Mn$\mathrm{Cp}$ bond length value for which one should expect spin-crossover to occur, and the corresponding ligand field associated. This value has been estimated to be around $1.752 \AA$ (measured as the $\mathrm{Mn}$ to the $\mathrm{Cp}$ ring centroid distance), with a corresponding ligand field of $15450 \mathrm{~cm}-1$ approximately (see SI). This means that any functionalization performed on the ring that forces the low-spin state to have a metal to ligand bond length larger than this cutoff value should not exhibit spin-crossover behavior, and rather remain in the high-spin state at all temperatures. This effect can be verified by analyzing some other functionalized systems such as the $\left[\left(\mathrm{Cp}_{1,2,3,4-}\right.\right.$

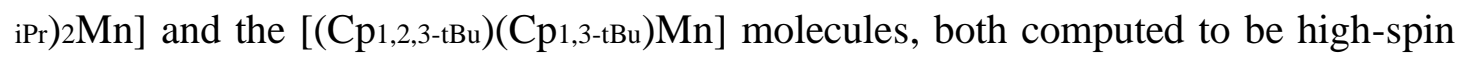
above $0 \mathrm{~K}$ (see SI).

\section{Discussion}

A useful starting point to discuss the interplay between electronic and steric effects in the fine tuning of the transition temperature in $\left[(\mathrm{CpR})_{2} \mathrm{Mn}\right]$ systems is the molecular orbital (MO) diagram for the simplest member of this family, this is, the manganocene itself. Even though this molecule has been extensively studied, and it is 
well known that it's crystal structure is a polymeric chain,36 and it's magnetic moment is only compatible with a high-spin $(\mathrm{S}=5 / 2)$ situation, 37 we can model the molecule as an isolated entity in both spin states using computational tools and use its MO diagrams as a starting point to analyze the different effects that ring functionalization will have over the spin-crossover behavior. A schematic molecular orbital diagram for the $\left[(\mathrm{Cp})_{2} \mathrm{Mn}\right]$ system is shown in figure 3 .

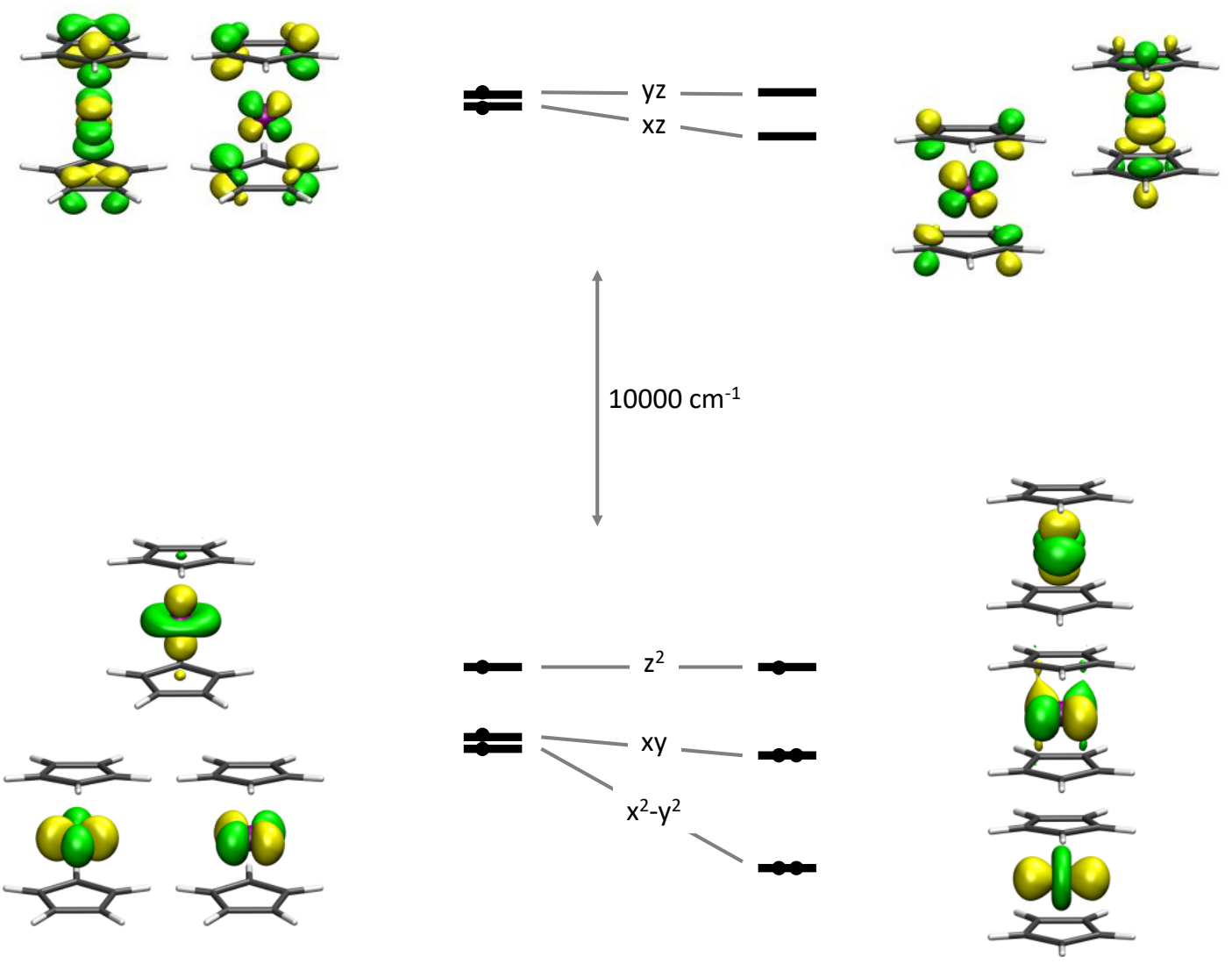

Figure 3: Schematic Molecular Orbital Diagram for the $[\mathrm{Mn}(\mathrm{Cp}) 2]$ system in high(left) and low-spin (right) states.

From Figure 3, the first thing that can be observed is that in both spin states there are two sets of orbitals that can be clearly distinguished: the set of non-bonding orbitals, composed by the $\mathrm{d}_{\mathrm{x} y}, \mathrm{~d}_{\mathrm{x} 2} \mathrm{-y} 2$ and $\mathrm{d}_{\mathrm{z} 2}$ orbitals, and the set of antibonding orbitals, composed by the $d_{x z}$ and $d_{y z}$ orbitals. This means that the control of the 
energy gap between this two sets of orbitals, and by extension the spin-crossover properties of these systems, is going to be controlled by the interaction between the frontier molecular orbitals of the cyclopentadienyl ligand and the $d_{x z}$ and $d_{y z}$ orbitals. The set of non-bonding orbitals is going to remain as it is, regardless of whatever functionalization occurs on the Cp ligand, due to the lack of interaction between the frontier molecular orbitals of the metal and the ligand (the orbitals are purely nonbonding), and its effect on tuning the SCO properties is going to be negligible.

Functionalization of the $\mathrm{Cp}$ ligand with methyl groups, an electron donating group, increases the localization of the ligand's frontier molecular orbitals, and raises its energy, as can be seen from Table 2 and Figure 2. Also, in Figure 4 we shown an schematic representation of the MO diagram for the $\left[(\mathrm{Cp} n-\mathrm{Me})_{2} \mathrm{Mn}\right]$ family $(\mathrm{n}=1,2,3$ and 4), reflects the increase in energy of the $d_{x z}$ and $d_{y z}$ orbitals as a result of the methyl functionalization on the $\mathrm{Cp}$ ligands. However, such functionalization minimizes possible steric congestions between both rings, and leads to geometries in which the metal-ligand bond length is almost unaltered. Therefore, the result over the SCO behavior in such family is that by increasing the number of methyl groups added to the $\mathrm{Cp}$ ligand, we progressively favor the low-spin state, thus increasing the expected transition temperature, and moving from a SCO system, the $\left[(\mathrm{Cp} 1-\mathrm{Me})_{2} \mathrm{Mn}\right]$, to a low-spin molecule, the $\left[(\mathrm{Cp} *)_{2} \mathrm{Mn}\right]$.

A similar effect therefore should be expected when adding other electron donating groups, such as isopropyl or tert-butyl, and, as a matter of fact, this is what happens in both $\left[\left(\mathrm{Cp}_{1-\mathrm{iPr}}\right)_{2} \mathrm{Mn}\right]$ and $\left[\left(\mathrm{Cp}_{1-\mathrm{tBu}}\right)_{2} \mathrm{Mn}\right]$ when comparing the energy splitting between non-bonding and antibonding orbitals with the same energy gap for the naked $\left[(\mathrm{Cp})_{2} \mathrm{Mn}\right]$ (see Table 2). However, as soon as we add more substituents of such type into the $\mathrm{Cp}$ ligand, the steric congestion forces the rings to move a part, thus 
reducing the interaction between the $\mathrm{Cp}$ frontier molecular orbitals and the $\mathrm{d}_{\mathrm{xz}}$ and $\mathrm{d}_{\mathrm{yz}}$ orbitals. Thus, the energy of those orbitals goes down, and the progressive functionalization of the $[(\mathrm{Cp}$-i $\mathrm{Pr}) 2 \mathrm{Mn}]$ and $\left[(\mathrm{Cp}-\mathrm{BBu})_{2} \mathrm{Mn}\right]$ families moves us from SCO molecules to high-spin systems. In Figure 4, and schematic MO diagram for such families, showing the progressive decrease in energy due to the loss of antibonding character of the $\mathrm{d}_{\mathrm{xz}}$ and $\mathrm{d}_{\mathrm{yz}}$ pair of orbitals.

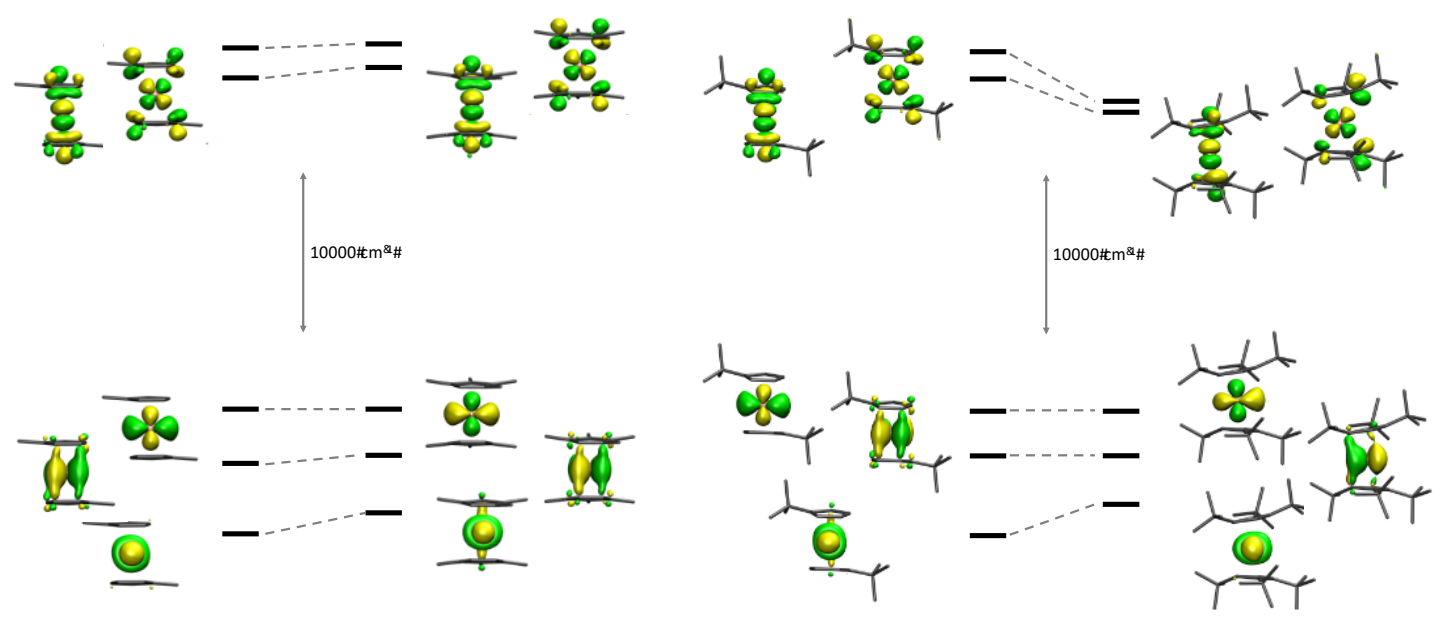

Figure 4: Left, Walsh diagram for $\left[(\mathrm{Cpn}-\mathrm{Me})_{2} \mathrm{Mn}\right]$ family, showing the limiting cases

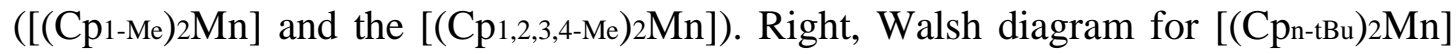
family, showing the limiting cases $\left(\left[\left(\mathrm{Cp}_{1-\mathrm{tBu}}\right)_{2} \mathrm{Mn}\right]\right.$ and the $\left[(\mathrm{Cp} 1,2,3,4-\mathrm{tBu})_{2} \mathrm{Mn}\right]$ systems $)$.

\section{Conclusions}

In this work, a computationally study of the spin-crossover properties in manganocene systems of general formula $\left[\left(\mathrm{Cp}_{n-\mathrm{R}}\right)_{2} \mathrm{Mn}\right]\left(\mathrm{R}=\mathrm{Me},{ }_{i} \operatorname{Pr}\right.$ and $\mathrm{t} \mathrm{Bu}, \mathrm{n}=1,2$, 3 and 4) has been presented. Using the OPBE functional with a triple- $\zeta$ basis set with polarization functions on all atoms, the experimental behavior of such systems is correctly reproduced. More importantly, our calculations allow us to gain insight into the delicate equilibrium between electronic and steric effects, which are at play in controlling the spin-crossover behavior in such systems. 
From the electronic structure point of view, the control of the transition temperature as well as the stabilization of the high-spin state or the low-spin state can be fully rationalized by analyzing the underlying electronic structure of the studied systems using a molecular orbital depiction. All studied systems have two sets of dbased molecular orbitals, the non-bonding set, formed by the $d_{x y}, d_{x} 2-y 2$ and $d_{z 2}$ orbitals, and the set of antibonding orbitals, which includes the low remaining d-based molecular orbitals, the $\mathrm{d}_{\mathrm{xz}}$ and $\mathrm{d}_{\mathrm{yz}}$. The degree of antibonding character in the later is going to be key in controlling the spin-crossover properties of such systems. Electron donating groups, such as methyl, isopropyl and tert-butyl can be used to functionalize the cyclopentadienyl ring. This functionalization increases the energy gap between non-bonding and antibonding orbitals, thus leading to higher transition temperatures. Addition of more than one methyl group keeps increasing the transition temperature, to the point that beyond the $\left[\left(\mathrm{Cp}_{1,3,4-\mathrm{Me}}\right)_{2} \mathrm{Mn}\right]$ system, the molecules become low-spin systems due to the energetic penalty cost that has the occupation of the pair of antibonding orbitals $\mathrm{d}_{\mathrm{xz}}$ and $\mathrm{d}_{\mathrm{yz}}$. However, by adding two or three isopropyl or tertbutyl groups, the opposite behavior appears, and a progressive decrease in the transition temperature leads to a high-spin situation for both $\left[\left(\mathrm{Cp}_{1,3,4-\mathrm{iPr}}\right)_{2} \mathrm{Mn}\right]$ and [(Cp1,3,4-tBu $\left.)_{2} \mathrm{Mn}\right]$ systems. This can be explained because of the progressive loss of antibonding character experienced by the $\mathrm{d}_{\mathrm{xz}}$ and $\mathrm{d}_{\mathrm{yz}}$ pair of orbitals as a result of the steric congestion imposed by the alkane substituents, that push the cyclopentadienyl rings away from each other, increasing the metal-ligand bond and therefore reducing the energy gap between both sets of orbitals. It is important to stress that we estimated the critical bond length to be $1.752 \AA$, meaning that any functionalization on the $\mathrm{Cp}$ rings that leads to similar bond lengths should also suppress the SCO behavior in favor of a high-spin system. 
An important point outlined from the presented calculations is the delicate interplay between steric and electronic effects in terms of tuning the transition temperature in manganocene systems. Even though at first glare one might expect to increase the transition temperature by adding electron donating groups, sterics can counterbalance this effect, and eventually lead to the opposite situation, which one more time points out how difficult can be to foresee the effect of a given chemical modification over the SCO behavior in a given system, and reinforces the idea that theoretical modeling can provide with trends in such behavior, trends that can be of great help in the rational design of new molecules with tailored properties.

\section{Associated Content:}

Cartesian coordinates with the corresponding energy and first frequency for every computed geometries in all spin-states are available in the electronic supporting information.

\section{Author information:}

jordi.cirera@qi.ub.es

eliseo.ruiz@qi.ub.es

Notes: The authors declare no competing financial interest.

\section{Acknowledgments:}

The research reported here was supported by the Spanish Ministerio de Economía y Competitividad (grant CTQ2015-64579-C3-1-P, MINECO/FEDER, UE). E.R. thanks Generalitat de Catalunya for an ICREA Academia award. We thankfully acknowledge the computer resources in the Consorci Serveis Universitaris de Catalunya (CSUC). 


\section{References:}

1. T. J. Kealy and P. L. Pauson, Nature, 1951, 168, 1039-1040.

2. S. A. Miller, J. A. Tebboth and J. F. Tremaine, J. Chem. Soc., 1952, 632-635.

3. Metallocenes: Synthesis Reactivity Applications, Wiley-VCH Verlag GmbH, 2008.

4. C. Elschenbroich, Organometallics, 3rd, completely rev. and extended edn., Wiley-VCH, Weinheim, 2006.

5. J. F. Hartwig, Organotransition metal chemistry : from bonding to catalysis, University Science Books, Sausalito, Calif., 2010.

6. R. D. Rogers, J. L. Atwood, D. Foust and M. D. Rausch, J. Cryst. Mol. Struct., 1981, 11, 183-188.

7. K. R. Flower and P. B. Hitchcock, J. Organomet. Chem., 1996, 507, 275-277.

8. R. A. Layfield, Chem. Soc. Rev., 2008, 37, 1098-1107.

9. M. Y. Antipin, R. Boese, N. Augart and G. Schmid, Struct. Chem., 1993, 4, 91-101.

10. E. O. Fischer and W. Pfab, Z. Naturforsch. B Chem. Sci., 1952, 7, 377-379.

11. P. Gütlich and H. A. Goodwin, Spin crossover in transition metal compounds, Springer, Berlin ; New York, 2004.

12. M. D. Walter, C. D. Sofield, C. H. Booth and R. A. Andersen, Organometallics, 2009, 28, 2005-2019.

13. J. C. Smart and J. L. Robbins, J. Am. Chem. Soc., 1978, 100, 3936-3937.

14. D. Cozak, F. Gauvin and J. Demers, Can. J. Chem., 1986, 64, 71-75.

15. J. Cirera and F. Paesani, Inorg. Chem., 2012, 51, 8194-8201.

16. J. Cirera and E. Ruiz, J. Mater. Chem. C, 2015, 3, 7954-7961.

17. J. Cirera and E. Ruiz, Inorg. Chem., 2016, 55, 1657-1663.

18. M. J. Frisch, G. W. Trucks, H. B. Schlegel, G. E. Scuseria, M. A. Robb, J. R. Cheeseman, G. Scalmani, V. Barone, B. Mennucci, G. A. Petersson, H. Nakatsuji, M. Caricato, X. Li, H. P. Hratchian, A. F. Izmaylov, J. Bloino, G. Zheng, J. L. Sonnenberg, M. Hada, M. Ehara, K. Toyota, R. Fukuda, J. Hasegawa, M. Ishida, T. Nakajima, Y. Honda, O. Kitao, H. Nakai, T. Vreven, J. A. Montgomery Jr., J. E. Peralta, F. Ogliaro, M. J. Bearpark, J. Heyd, E. N. Brothers, K. N. Kudin, V. N. Staroverov, R. Kobayashi, J. Normand, K. Raghavachari, A. P. Rendell, J. C. Burant, S. S. Iyengar, J. Tomasi, M. Cossi, N. Rega, N. J. Millam, M. Klene, J. E. Knox, J. B. Cross, V. Bakken, C. Adamo, J. Jaramillo, R. Gomperts, R. E. Stratmann, O. Yazyev, A. J. Austin, R. Cammi, C. Pomelli, J. W. Ochterski, R. L. Martin, K. Morokuma, V. G. Zakrzewski, G. A. Voth, P. Salvador, J. J. Dannenberg, S. Dapprich, A. D. Daniels, Ö. Farkas, J. B. Foresman, J. V. Ortiz, J. Cioslowski and D. J. Fox, Gaussian 09, Rev. D01, 2009.

19. N. C. Handy and A. J. Cohen, Mol. Phys., 2001, 99, 403-412.

20. W.-M. Hoe, A. J. Cohen and N. C. Handy, Chem. Phys. Lett., 2001, 341, 319328.

21. J. P. Perdew, K. Burke and M. Ernzerhof, Phys. Rev. Lett., 1996, 77, $3865-$ 3868 . 
22. J. P. Perdew, K. Burke and M. Ernzerhof, Phys. Rev. Lett., 1997, 78, 13961396.

23. E. A. Bleda, C. Trindle and Z. Altun, Comp. Theor. Chem., 2015, 1073, 139148.

24. J. Conradie and A. Ghosh, J. Phys. Chem. B, 2007, 111, 12621-12624.

25. B. J. Houghton and R. J. Deeth, Eur. J. Inorg. Chem., 2014, 4573-4580.

26. F. Shahbazi-Raz, M. Adineh, N. Safari and M. Zahedi, Int. J. Quantum Chem., 2016, 116, 1179-1186.

27. J. Sirirak, D. Sertphon, W. Phonsri, P. Harding and D. J. Harding, Int. J. Quantum Chem., 2017, 117.

28. M. Swart, J. Chem. Theory Comput., 2008, 4, 2057-2066.

29. M. Swart, Int. J. Quantum Chem., 2013, 113, 2-7.

30. S. Ye and F. Neese, Inorg. Chem., 2010, 49, 772-774.

31. V. N. Staroverov, G. E. Scuseria, J. M. Tao and J. P. Perdew, J. Chem. Phys., 2003, 119, 12129-12137.

32. J. M. Tao, J. P. Perdew, V. N. Staroverov and G. E. Scuseria, Phys. Rev. Lett., 2003, 91, 146401.

33. A. Schäfer, C. Huber and R. Ahlrichs, J. Chem. Phys., 1994, 100, 5829-5835.

34. M. E. Casida, C. Jamorski, K. C. Casida and D. R. Salahub, J. Chem. Phys., 1998, 108, 4439-4449.

35. G. Zhang and C. B. Musgrave, J. Phys. Chem. A, 2007, 111, 1554-1561.

36. W. Bunder and E. Weiss, Z. Naturforsch. B Chem. Sci., 1978, 33, 1235-1237.

37. G. Wilkinson, F. A. Cotton and J. M. Birmingham, J. Inorg. Nucl. Chem., 1956, 2, 95-113. 